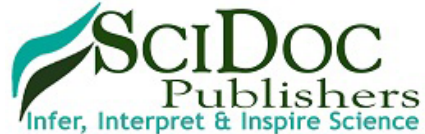

\section{Knowledge, Attitude and Practices Regarding Child Abuse Among School Teachers: A Cross-Sectional Study}

International Journal of Dentistry and Oral Science (IJDOS) ISSN: 2377-8075

Research Article

M.P. Induja ${ }^{1}$, Sujatha Somasundaram ${ }^{2}$, M.P. Santhosh Kumar $^{3 *}$

${ }^{1}$ Department of Pedodontics, Saveetha Dental College and Hospital, Saveetha University, India.

${ }^{2}$ Reader, Department of Pedodontics, Saveetha Dental College and Hospital, Saveetha University, India.

${ }^{3}$ Reader, Department of Oral and Maxillofacial Surgery, Saveetha Dental College and Hospital, Saveetha Institute of Medical and Technical Sciences (SIMATS), Saveetha University 162, Poonamallee High Road, Velappanchavadi, Chennai 600077 Tamil Nadu, India.

\title{
Abstract
}

Objectives: Child abuse and neglect is still a serious social and public health problem. The damage to a child from maltreatment can range from minor to extensive physical, psychological, and behavioral problems. In the most severe cases, child abuse and neglect results in the tragic death of a child.Teachers are in a unique position to identify and report abuse because of their daily contact with young children. The aim of this study was to investigate school teacher's knowledge, attitude and practices regarding child abuse.

Methods: The questionnaire consisting of 10 questions was sent to teachers in government schools and private schools. Questionnaire was framed to assess teachers' knowledge about child abuse,their attitude towards reporting child abuse and their practices involved regarding child abuse.

Results: $36.3 \%$ were government school teachers, $21.8 \%$ were private sector CBSE and $41.9 \%$ were private matriculation teachers. $82 \%$ of the teachers agreed that it should be mandated to report about child abuse. $64.7 \%$ of the teachers made report of child abuse cases and $35.3 \%$ of the teachers failed to report child abuse cases. $57.7 \%$ of the teachers have planned to report of child abuse cases when they suspect it, $18.2 \%$ of the teachers have not planned to report child abuse cases and $24.1 \%$ of the teachers have not decided yet to report child abuse cases when they suspect it.

Conclusion: Within, the limits of this study, it can be concluded that majority of the teachers have knowledge about child abuse, they are aware of the signs and symptoms of child abuse and child neglect but they are not reporting child abuse cases.

Keywords: Knowledge; Child Abuse; Teachers; Parent; Children; School; Attitude.

\section{Introduction}

Child abuse is any form of physical, sexual, neglect of a child especially by a parent or other caretaker [1]. This can lead to interference with the child's normal social or psychological development leaving the child with lifelong psychological scars [2]. Child abuse and neglect is motionless serious social and public health problem. Various signs to look out for child abuse are bruising, traumatic primary teeth fractures and unhealed scars [3-5]. The harm to a child can vary from slight to large physical, psychological, and behavioral problems. In the most serious cases, child abuse and neglect results in the devastating death of a child $[6,7]$.
Teachers are in an eccentric position to identify and report child abuse because of their daily contact with children. Several studies revealed that teachers receive nominal training in identifying child abuse $[8,9]$. Due to their absence of sufficient training, many teachers are not aware of the foremost symptoms of child abuse. Thus, child maltreatment may go unknown and confidential by many school personnel $[10,11]$.

A large-scale national study conducted in 2007 by Ministry of Women and Child Development (MoWCD), to assess the range and nature of child abuse in India, exhibited some alarming statis-

*Corresponding Author:

M.P. Santhosh Kumar,

Reader, Department of Oral and Maxillofacial Surgery, Saveetha Dental College and Hospital, Saveetha Institute of Medical and Technical Sciences (SIMATS), Saveetha University 162, Poonamallee High Road, Velappanchavadi, Chennai 600077 Tamil Nadu, India.

Tel: 9994892022

Email ID: santhoshsurgeon@gmail.com

Received: April 10, 2021

Accepted: May 02, 2021

Published: May 08, 202

Citation: M.P. Induja, Sujatha Somasundaram, M.P. Santhosh Kumar. Knowledge, Attitude and Practices Regarding Child Abuse Among School Teachers: A Cross-Sectional Study. Int J Dentistry Oral Sci. 2021;08(5):2405-2409. doi: http://dx.doi.org/10.19070/2377-8075-21000472

Copyright: M.P. Santhosh Kumar 2021 . This is an open-access article distributed under the terms of the Creative Commons Attribution License, which permits unrestricted use, distribution and reproduction in any medium, provided the original author and source are credited. 
tics. It revealed that among the 12,447 children interviewed, more than half (53 percent) reported experience of sexual abuse [12]. Child abuse can also be in the form of emotional abuse involving shaming, humiliating a child, making negative comparisons to others,constant yelling, threatening, rejecting and ignoring the child as punishment, having limited physical contact with the child [13-15]. Therefore, the aim of this study was to assess the knowledge, awareness and practice on child abuse against children among all school teachers in Indian population.

\section{Material and Methods}

An online survey was developed in google forms that contained 10 questions. The questionnaire was sent to teachers in government schools and private schools. The survey developed for this study contained 2 sections. The first section assessed the knowledge and their attitude toward child abuse reporting. The second section was about child abuse reporting experience during the past years. The survey was answered by 100 teachers. The results were collected and pie charts were obtained and interpreted.

\section{Result}

According to this survey, Figure 1 shows that $36.3 \%$ were government school teachers, $21.8 \%$ were private sector CBSE and $41.9 \%$ were private matriculation teachers. Figure 2 shows that $52.7 \%$ of teachers agreed that child abuse is a serious problem in our society while $47.3 \%$ of teachers disagreed. Figure 3 shows that $82 \%$ of the teachers agreed that it should be mandatoryto report about child abuse and $18 \%$ of the teachers disagreed with the statement. Figure 4 shows that $95 \%$ of the school teachers agreed to know the school procedures for reporting child abuse and 5\% of the school teachers did not know the school procedures for reporting child abuse. Figure 5 shows that $98.8 \%$ of the school teachers were aware of the signs of child abuse and $1.2 \%$ of the school teachers were not aware of the signs of child abuse. Figure 6 shows that $70.9 \%$ of the teachers agreed that it is parents right to discipline their children and $29.1 \%$ of the teachers disagreed. Figure 7 shows that $35.2 \%$ of the teachers agreed not reporting child abuse because of the possibility of being sued and $64.8 \%$ of the teachers disagreed. Figure 8 shows that $64.7 \%$ of the teachers made report of child abuse cases and $35.3 \%$ of the teachers failed to report child abuse cases. Figure 9 shows that $35 \%$ of the teachers have noticed an abused child but failed to report and $65 \%$ of the teachers disagreed.Figure 10 shows that $57.7 \%$ of the teachers have planned to report of child abuse cases when they suspect it, $18.2 \%$ of the teachers have not planned to report child abuse cases and $24.1 \%$ of the teachers have not decided yet to report child abuse cases when they suspect it.

\section{Discussion}

A study conducted by Crenshaw et al reported that teachers make good observations of children on a regular basis and compare present and past behavior [16]. The studies reported increased risks for psychiatric disorders including compulsive disorders, suicidal behaviors and also depression. The victims of child sexual abuse were also established to have increased risks for temperamental problems, poor social adjustment, lack of trust, and insecure relations with parents [17]. Research showed that the majority of teachers received minimal instruction on identifying, reporting, and intervening in suspected cases of child abuse and neglect [18].

In general, it was found that the majority of teachers had never made a report of child abuse. On the average, participants had 10 years teaching experience, but only made one report of child abuse [19]. A study conducted by Bavolek et al concluded that there are several reasons for failure to report on the part of school

Figure 1. Pie chart represents the distribution of the school teachers among different school curriculums. It shows that $21.8 \%$ of the teachers were among the private sector CBSE (yellow), 36.3\% of the teachers were among the government school(blue) and $41.9 \%$ teachers were among private matriculation(red).

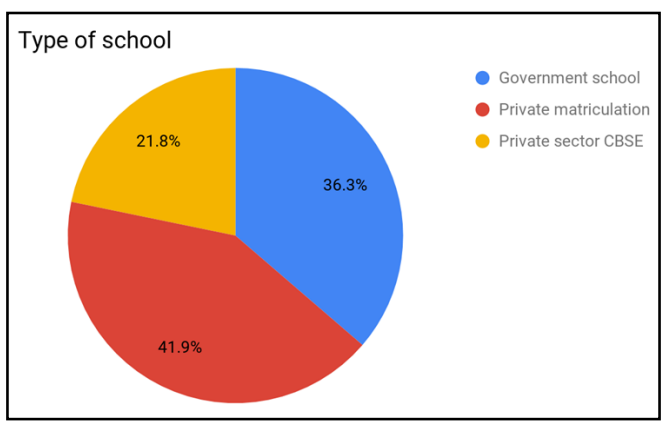

Figure 2. Pie chart represents the responses for whether the child abuse was a serious problem. $53 \%$ of the teachers agreed (orange) and $47 \%$ of the teachers disagreed (violet).

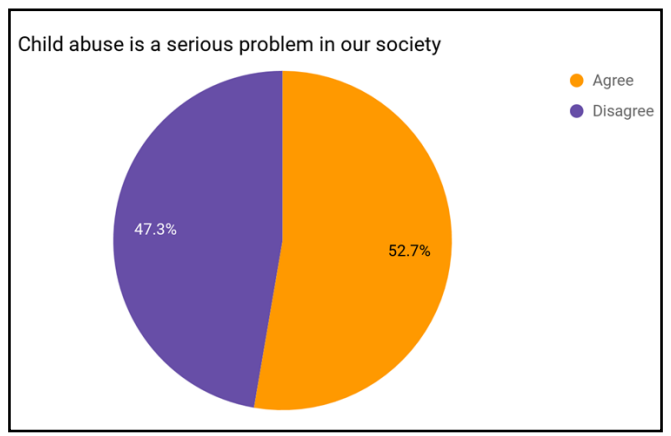


Figure 3. Pie chart represents the responses for whether the teachers should be mandated to reportchild abuse cases. $82 \%$ of the teachers agreed that it should be mandated to report about child abuse (orange) and $18 \%$ of the Teachers disagreed with the statement(violet).

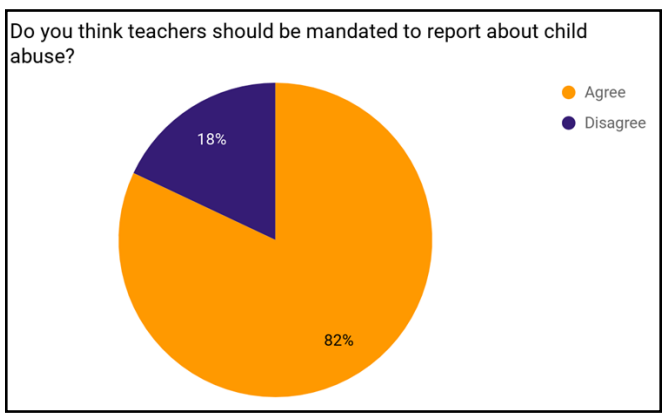

Figure 4. Pie chart represents the distribution of awareness to school procedure for reporting child abuse. $95 \%$ of the school teachers agreed that they knew the school procedures for reporting childabuse(orange) and 5\% of the school teachers did not know the school's procedures for reporting child abuse (violet).

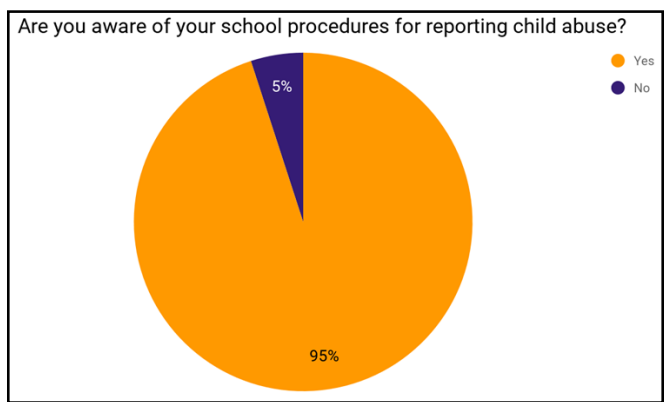

Figure 5. Pie chart represents the distribution of awareness of the signs of child abuse. $98.8 \%$ of the school teachers were aware of the signs of child abuse(orange) and $1.2 \%$ of the school teachers were not aware of the signs of child abuse (violet).

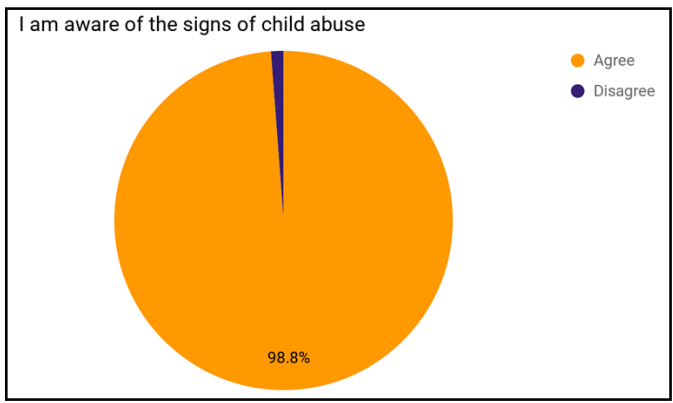

Figure 6. Pie chart represents the responses for whetherthe parents have right to discipline their children in any manner. $70.9 \%$ of the teachers agreed that it is the parents right to discipline their Children(violet) and $29.1 \%$ of the teachers disagreed(orange).

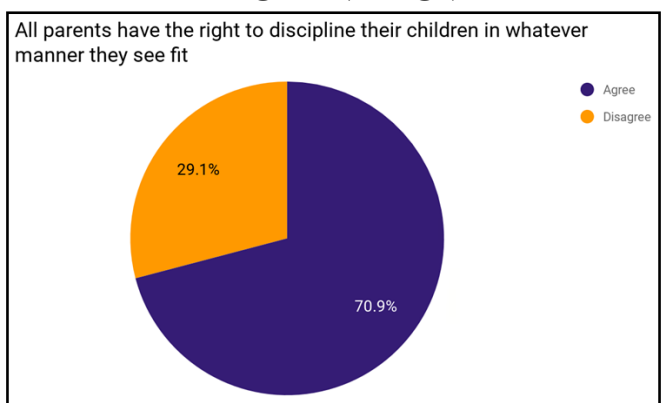

personnel. These include personal beliefs and biases, lack of knowledge or awareness of signs of abuse or of duty to report, and descriptions of past outcomes of previously reported cases [20]. Another study by Oberman et al reported that the most commonly cited reason for failure to report child abuse was fear of making an inaccurate report, followed by feeling as though child protective services does not offer help to maltreated children [21].
A study by Baxter and Beer (1990) reported that $16 \%$ of teachers were unaware of the law regarding child abuse reporting. In their study, they also found that less than one-fourth of school personnel had read the Kansas state law regarding child abuse, and only $28 \%$ of respondents knew that all school personnel were required to report suspected abuse [22].

Several studies revealed that teachers do not receive adequate 
Figure 7. Pie chart represents the responses of teachers for not reporting child abuse because of the possibility of being sued. It shows that $35.2 \%$ of the teachers agreed not reporting child abuse because of the possibility of being sued (violet) and $64.8 \%$ of the teachers disagreed(orange).

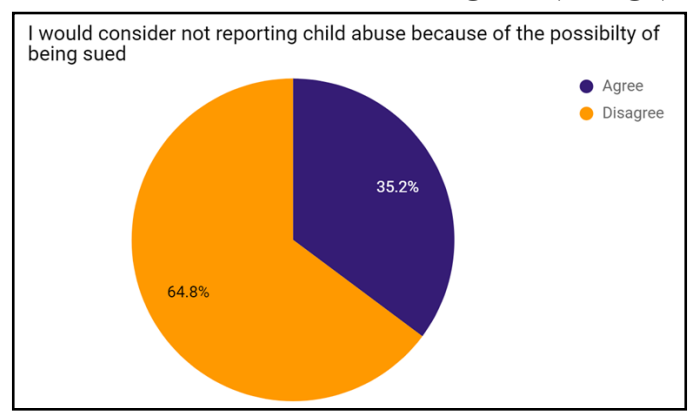

Figure 8. Pie chart represents the responses to whether child abuse reports to children's services were made by theteachers. $64.7 \%$ of the teachers made report of child abuse cases(blue) and $35.3 \%$ of the teachers failed to report child abuse cases(violet).

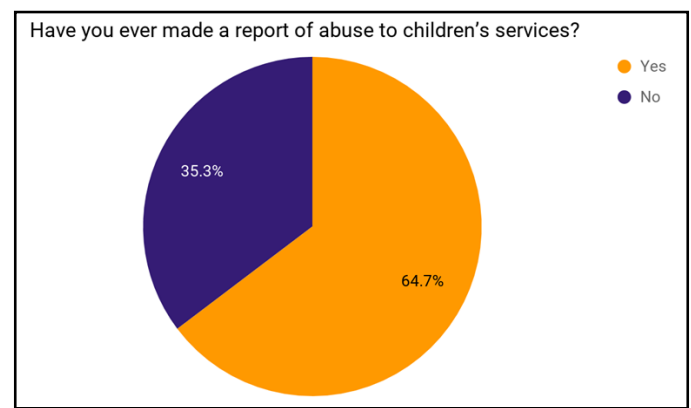

Figure 9. Pie chart represents responses of teachers regarding failure to report child abuse when present. $65 \%$ of the teachers disagreed (blue) and $35 \%$ of the teachers agreed (orange).

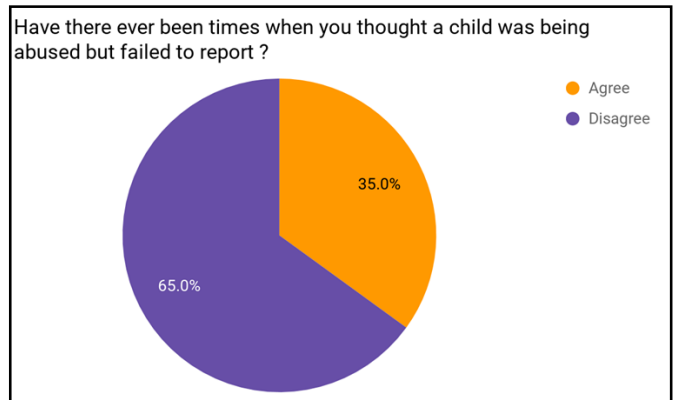

Figure 10. Pie chart represents the responses of teachers planning to report child abuse if suspected. $57.7 \%$ of the teachers have planned to report of child abuse cases when they suspect it(orange),18.2\% of the teachers have not planned to report child abuse cases(violet) and $24.1 \%$ of the teachers have not decided yet to report child abuse cases when they suspect it(green).

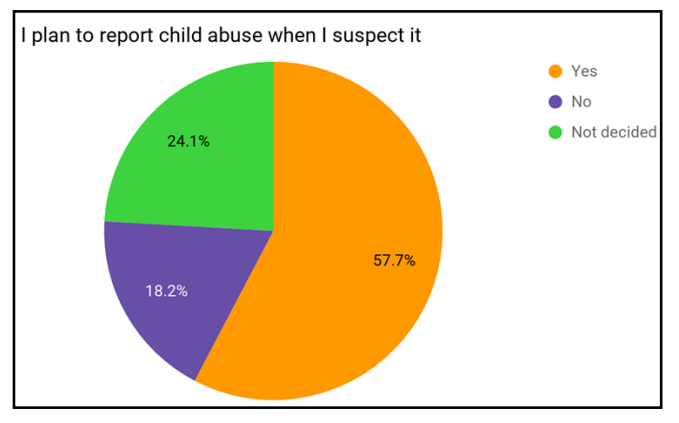

training on child abuse during their college education or in-service training programs [23-26]. McIntyre (1987) found that only $33 \%$ of the teachers reported that they knew the existence of their state law. According to their study, $81 \%$ of teachers received no child abuse training during their college career, $61 \%$ had not received information on child abuse or neglect during in-service training sessions and only $30 \%$ of the teachers said they were very aware of the symptoms of neglect, $21 \%$ of the symptoms of physical abuse, $19 \%$ of the signs of emotional abuse, and $4 \%$ of the symptoms of sexual abuse [27].

Kirk A. Beck et al, reported that almost two-thirds of teachers felt that a significant obstacle to child abuse reporting was the lack of sufficient knowledge on how to detect and report cases of suspected child abuse [28]. Yashika Sharma et al, reported that majority of the parents lack knowledge regarding children's edu- 
cation and protection.Most parents were in favor of having better career prospects for Male child.Parents were also asked regarding the physical, mental, and emotional health of a child.Most of the parents were of the opinion that children should be distinguished based on academic performance.The study also recommended various measures to combat child abuse [29].

\section{Conclusion}

Within the limits of this study, it can be concluded that most of the teachers were aware about child abuse but failed to report it confidently. The education about reporting child abuse is urgently needed because of the consequences of the problem. The schools should work as a team in reporting child abuse and there should be proper communications between the principal, teacher, counsellor, social worker, child, and parents, which aids them in feeling more confident in making reports of child abuse.

\section{References}

[1]. Patil SB, Udapi G. A study to assess the effectiveness of structured teaching program on knowledge regarding child abuse and its prevention among primary school teachers in selected government primary schools of Belgaum City, Karnataka. Asian Journal of Nursing Education and Research. 2015;5(1):26.

[2]. Davey RI, Hill J. A study of the variability of training and beliefs among professionals who interview children to investigate suspected sexual abuse. Child Abuse Negl. 1995 Aug;19(8):933-42. Pubmed PMID: 7583752.

[3]. Ravikumar D, Jeevanandan G, Subramanian EMG. Evaluation of knowledge among general dentists in treatment of traumatic injuries in primary teeth: A cross-sectional questionnaire study. Eur J Dent. 2017 AprJun;11(2):232-237. Pubmed PMID: 28729799.

[4]. Vignesh Ravindran, Rekha V, Annamalai S, Norouzi-Baghkomeh P, Sharmin D. A case report on dental management of a toddler with Pachygyria. J Clin Exp Dent. 2017 May 1;9(5):e726-e728. Pubmed PMID: 28512554.

[5]. Ramadurai N, Gurunathan D, Samuel AV, Subramanian E, Rodrigues SJL. Effectiveness of 2\% Articaine as an anesthetic agent in children: randomized controlled trial. Clin Oral Investig. 2019 Sep;23(9):3543-3550. Pubmed PMID: 30552590

[6]. Kenny MC. Teachers' attitudes toward and knowledge of child maltreatment. Child Abuse Negl. 2004 Dec;28(12):1311-9. Pubmed PMID: 15607772.

[7]. Ravindra V, Rekha V, Annamalai S, Sharmin D, Norouzi-Baghkomeh P. A comparative evaluation between dermatoglyphic patterns and different terminal planes in primary dentition. J Clin Exp Dent. 2018 Dec 1;10(12):e1149-e1154. Pubmed PMID: 30697372.

[8]. O'Toole R, Webster SW, O'Toole AW, Lucal B. Teachers' recognition and reporting of child abuse: a factorial survey. Child Abuse Negl. 1999 Nov;23(11):1083-101. Pubmed PMID: 10604064.

[9]. Panchal V, Jeevanandan G, Subramanian E. Comparison of instrumentation time and obturation quality between hand $\mathrm{K}$-file, $\mathrm{H}$-files, and rotary Kedo-S in root canal treatment of primary teeth: A randomized controlled trial. J Indian Soc Pedod Prev Dent. 2019 Jan-Mar;37(1):75-79. Pubmed PMID: 30804311.
[10]. Goldman JD, Grimbeek P. Child sexual abuse and mandatory reporting intervention preservice content preferred by student teachers. J Child Sex Abus. 2014;23(1):1-16. Pubmed PMID: 24393087.

[11]. Bourke A, Maunsell C. 'Teachers matter': The impact of mandatory reporting on teacher education in Ireland. Child abuse review. $2016 \mathrm{Jul} ; 25(4): 314-$ 24.

[12]. Kacker L, Mohsin N, Dixit A, Varadan S, Kumar P. Study on child abuse: India, 2007. Ministry of Women and child development, Government of India; 2007.

[13]. Abrahams N, Casey K, Daro D. Teachers' knowledge, attitudes, and beliefs about child abuse and its prevention. Child Abuse Negl. 1992;16(2):22938. Pubmed PMID: 1559171

[14]. Jeevanandan G, Ganesh S; Arthilakshmi. Kedo file system for root canal preparation in primary teeth. Indian J Dent Res. 2019 Jul-Aug;30(4):622-624. Pubmed PMID: 31745062

[15]. Ramakrishnan M, Dhanalakshmi R, Subramanian EMG. Survival rate of different fixed posterior space maintainers used in Paediatric Dentistry - A systematic review. Saudi Dent J. 2019 Apr;31(2):165-172. Pubmed PMID: 30983825.

[16]. Crenshaw WB, Crenshaw LM, Lichtenberg JW. When educators confront child abuse: an analysis of the decision to report. Child Abuse Negl. 1995 Sep;19(9):1095-113. Pubmed PMID: 8528816.

[17]. Krishnakumar P, Satheesan K, Geeta MG, Sureshkumar K. Prevalence and spectrum of sexual abuse among adolescents in Kerala, South India. Indian J Pediatr. 2014 Aug;81(8):770-4. Pubmed PMID: 24154965.

[18]. Reiniger A, Robison E, McHugh M. Mandated training of professionals: a means for improving reporting of suspected child abuse. Child Abuse Negl. 1995 Jan;19(1):63-9. Pubmed PMID: 7895145.

[19]. Kenny MC. Child abuse reporting: teachers' perceived deterrents. Child Abuse Negl. 2001 Jan;25(1):81-92. Pubmed PMID: 11214815.

[20]. Bavolek SJ. Why aren't school personnel reporting child abuse in Wisconsin?. Teacher Education and Special Education. 1983 Jan;6(1):33-8.

[21]. Oberman A, Studer J, Eby-Meeks D. An investigation of school counselor and school counselor trainee activities. Michigan Journal of Counseling: Research, Theory and Practice. 2009;36(2):2.

[22]. Baxter G, Beer J. Educational needs of school personnel regarding child abuse and/or neglect. Psychol Rep. 1990 Aug;67(1):75-80. Pubmed PMID: 2236422.

[23]. Kumar MP. Dental management of patients on antiplatelet therapy: Literature update. Asian J Pharm Clin Res. 2016;9(3):26-31.

[24]. Kumar S. Newer delivery systems for local anesthesia in dentistry. J Pharm Sci Res. 2015;7(5):252-5.

[25]. Ahamed A, Kumar MS. Knowledge, attitude and perceived confidence in handling medical emergencies among dental students. Journal of Pharmaceutical Sciences and Research. 2016 Jul 1;8(7):645.

[26]. Kumar S. Knowledge, attitude and practices of dental students toward dental management of patients on antiplatelet therapy. Asian J Pharm Clin Res. 2016;9(30):270-6.

[27]. McIntyre TC. Teacher awareness of child abuse and neglect. Child Abuse Negl. 1987;11(1):133-5. Pubmed PMID: 3828867.

[28]. Beck KA, Ogloff JR, Corbishley A. Knowledge, compliance, and attitudes of teachers toward mandatory child abuse reporting in British Columbia. Canadian Journal of Education/Revue canadienne de l'education. 1994 Jan $1: 15-29$.

[29]. Sharma Y, Mathur K. Assessment of knowledge and attitude about child abuse amongst parents visiting rural tertiary care hospital in central India. J Family Med Prim Care. 2019 Nov 15;8(11):3525-3530. Pubmed PMID: 31803646. 